\title{
Namenregister Nr. 23
}

Ein vollständiger oder geklurzter Abdruck der Referate ist ohne Genehmigung der Redaktion und des Verlages verboten!

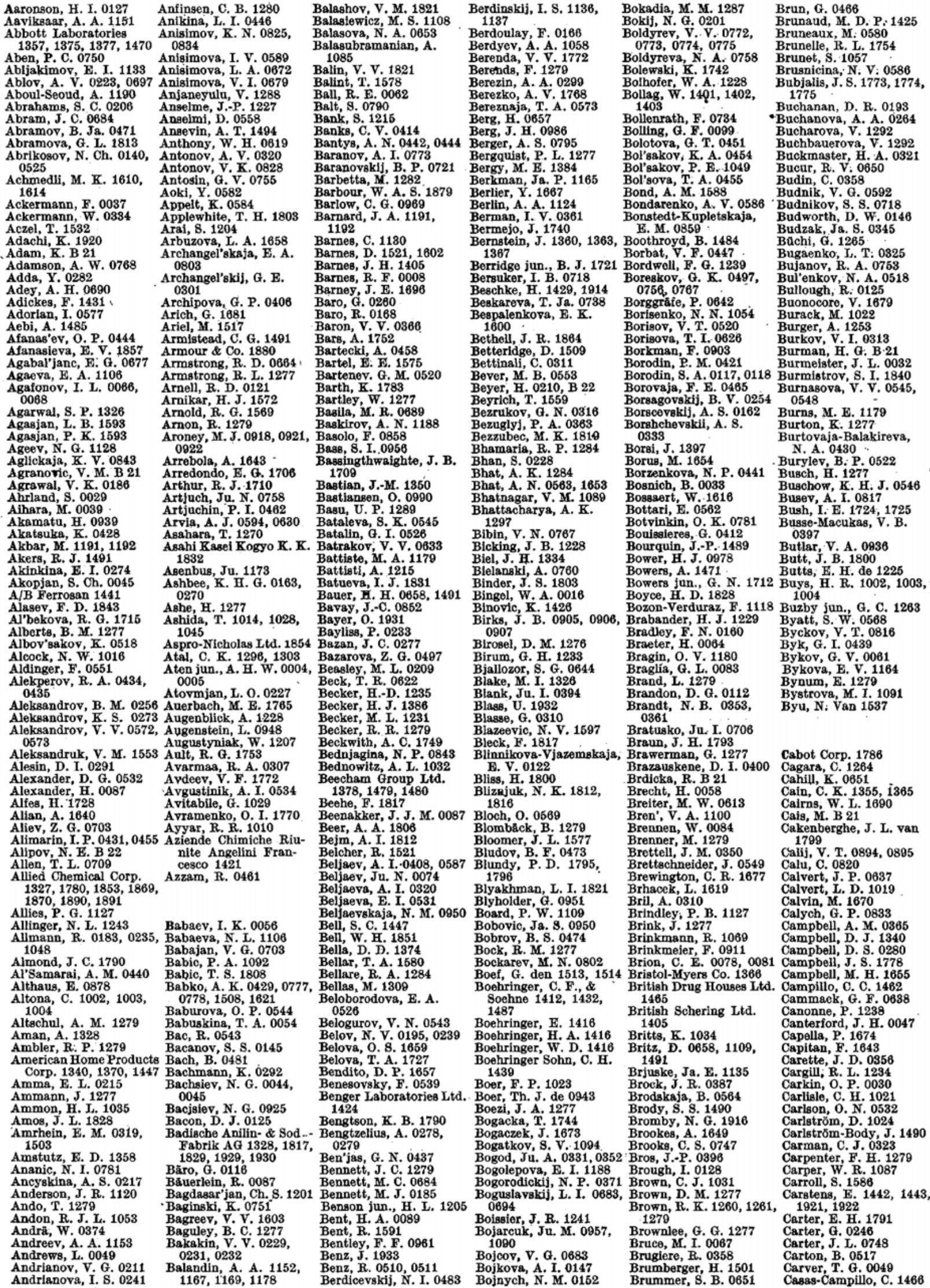




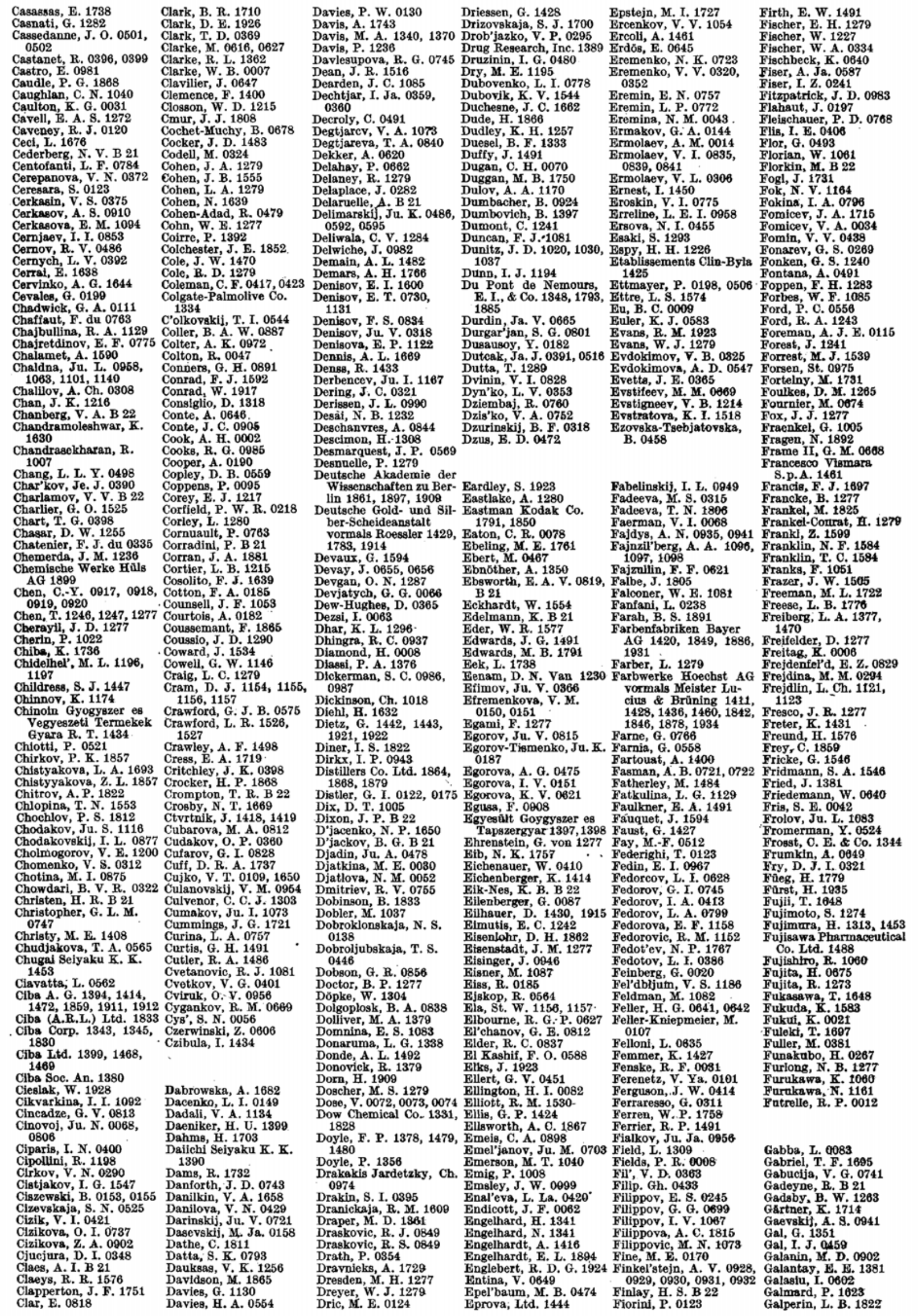




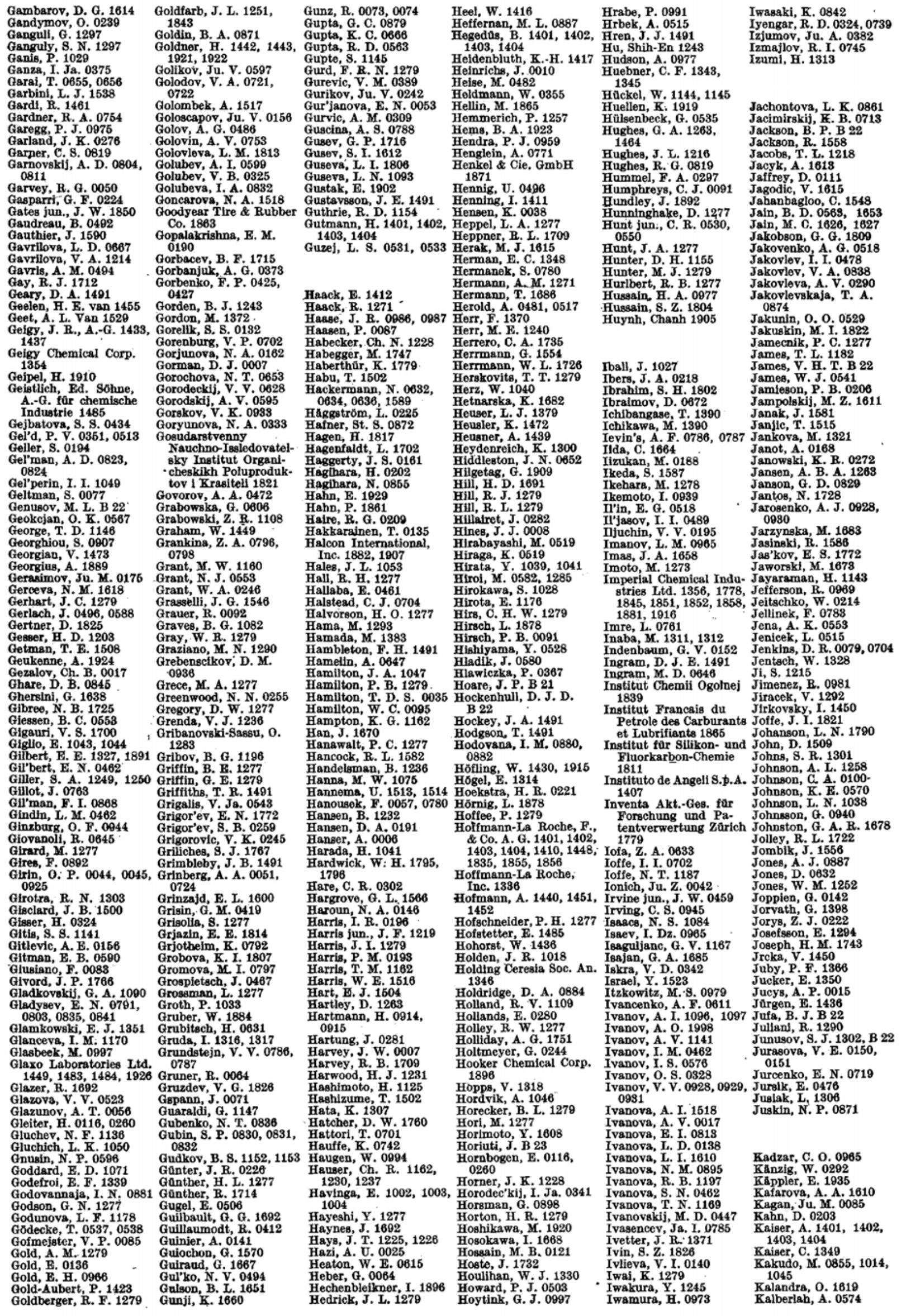




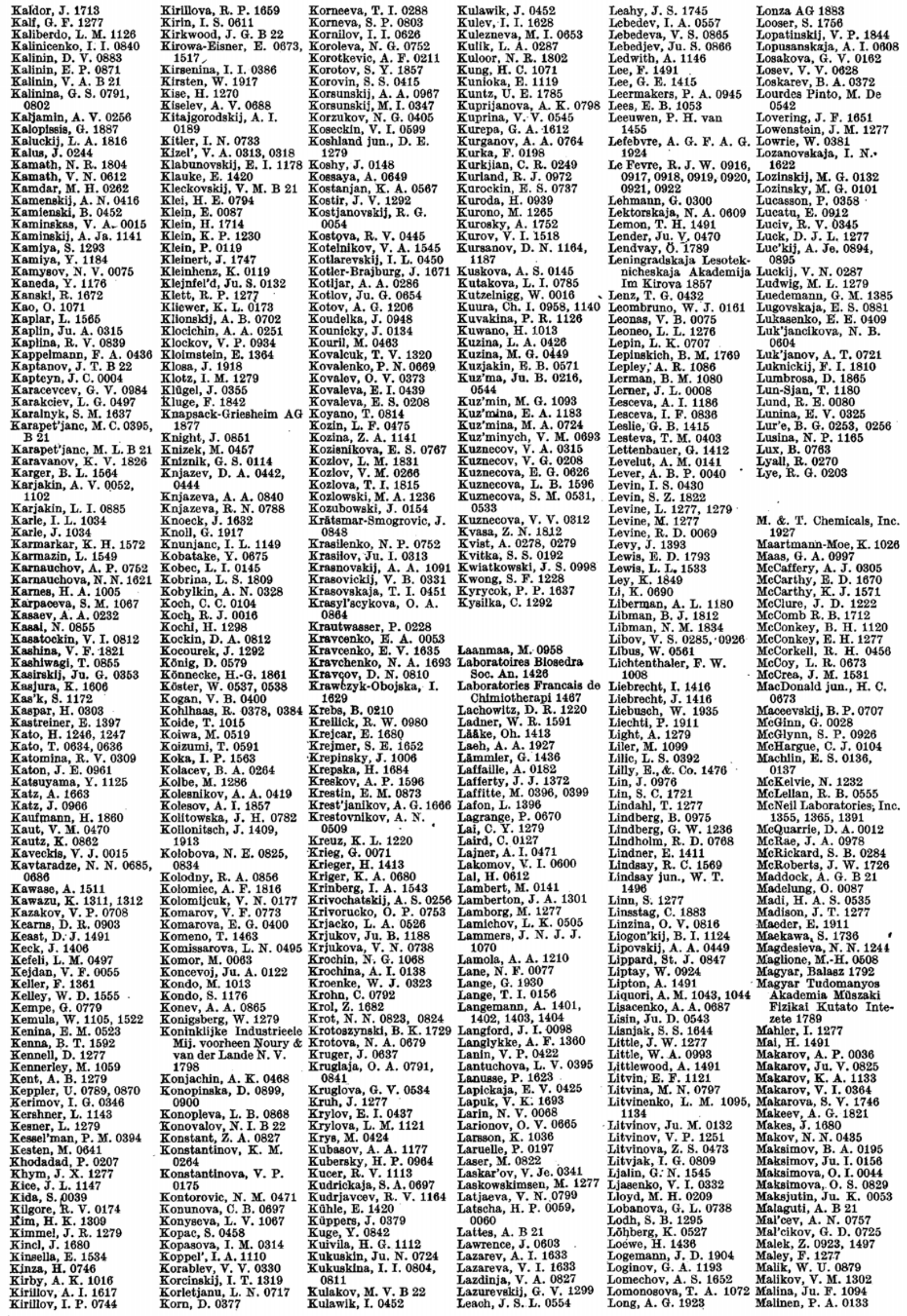




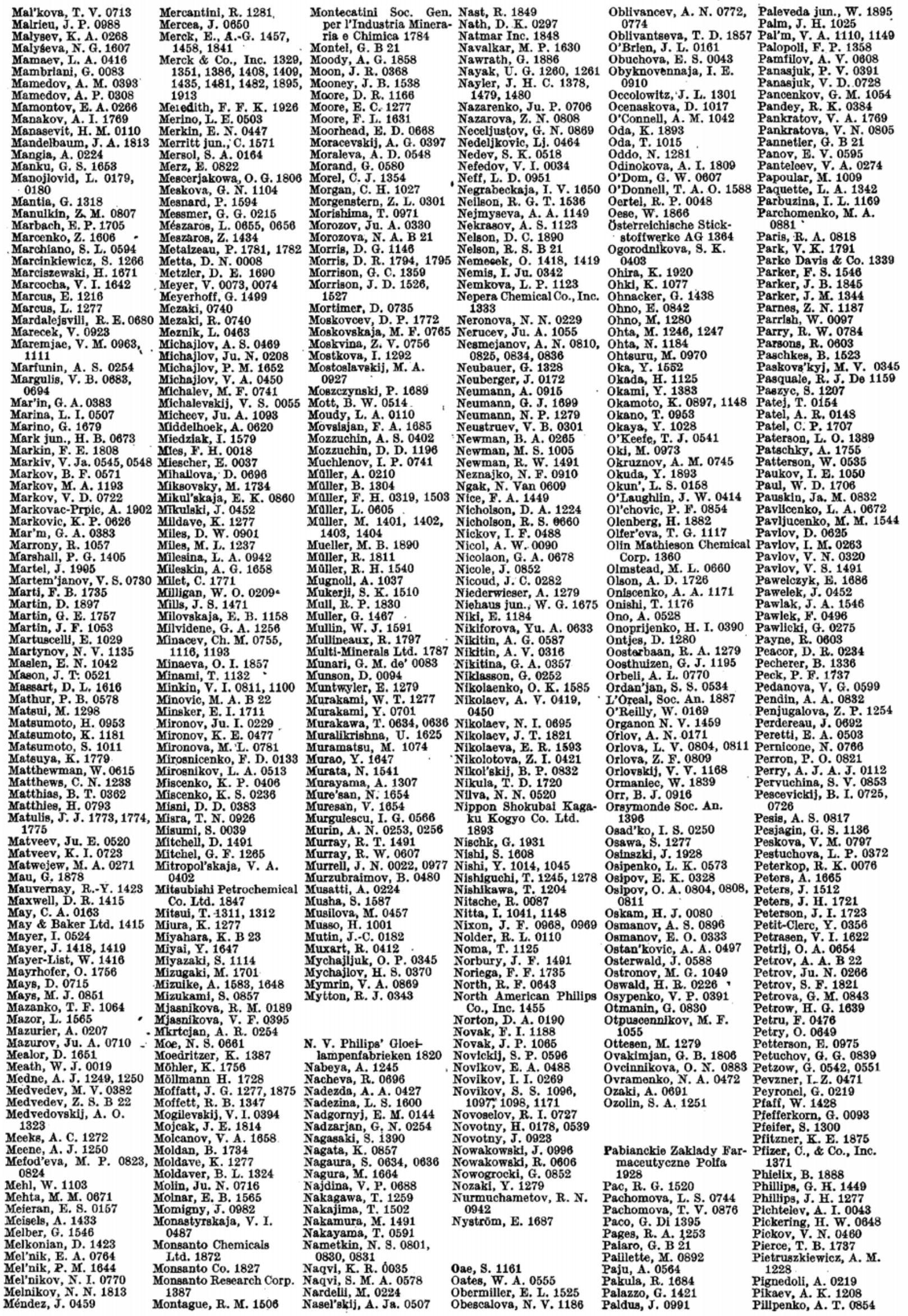




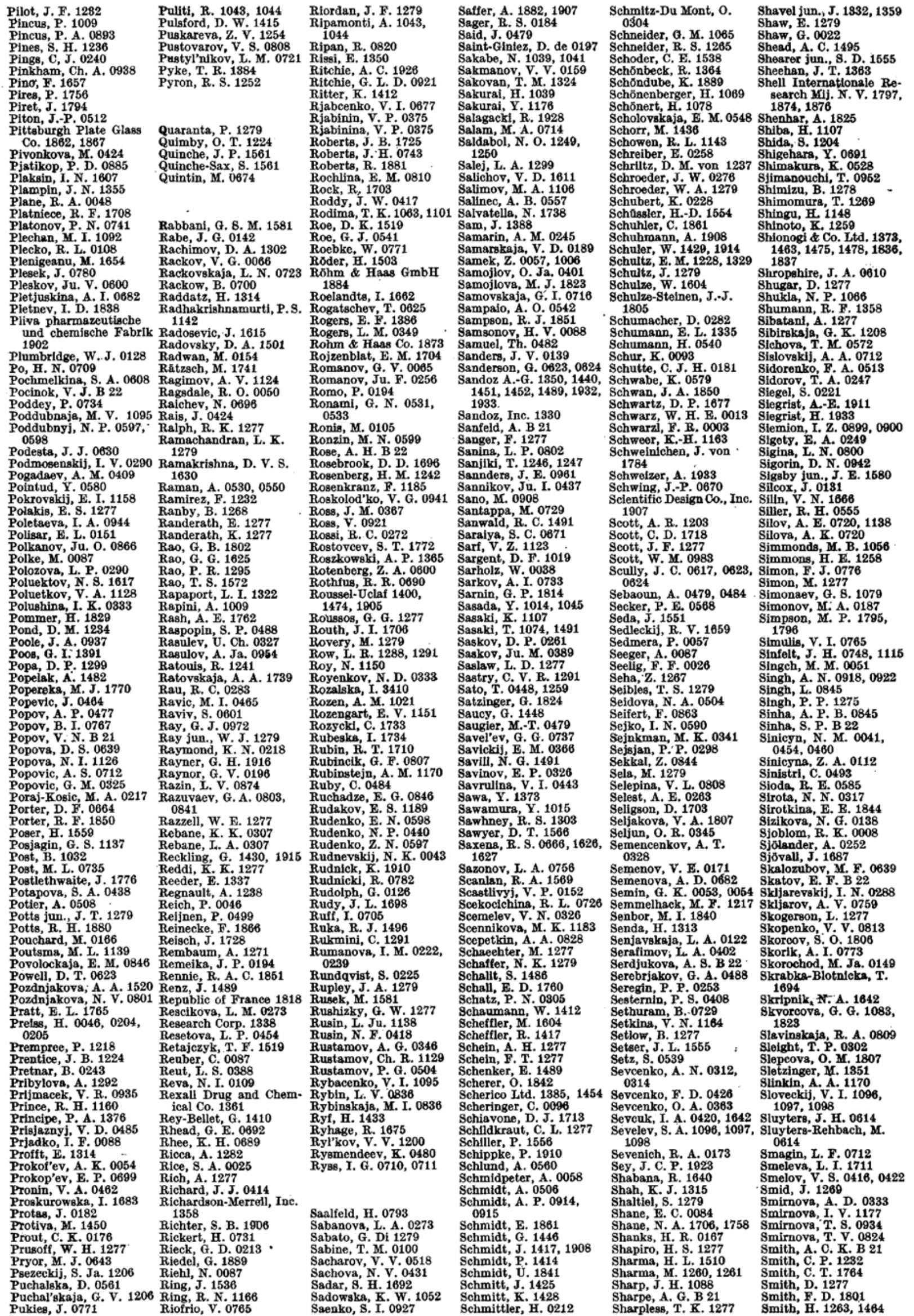




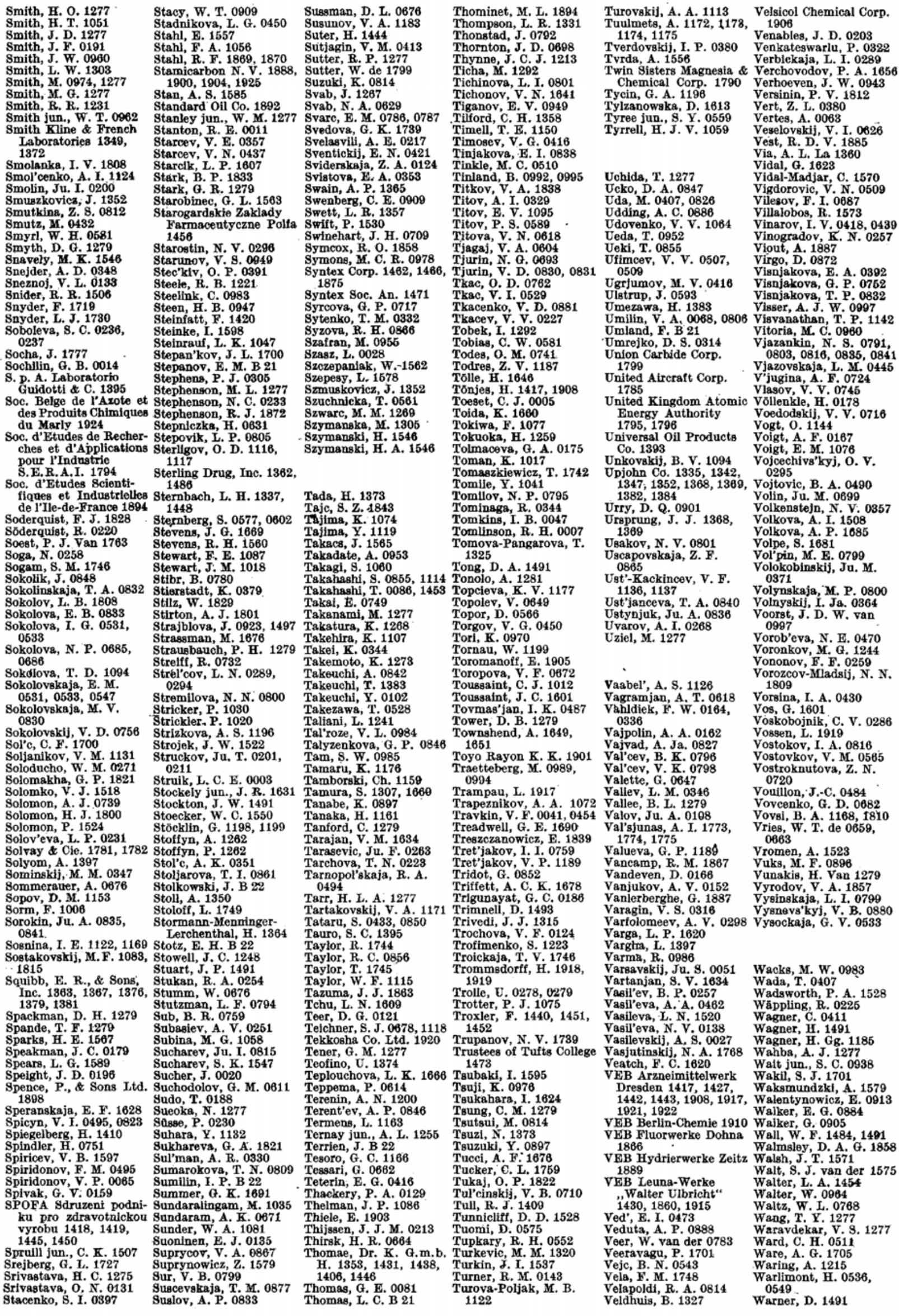




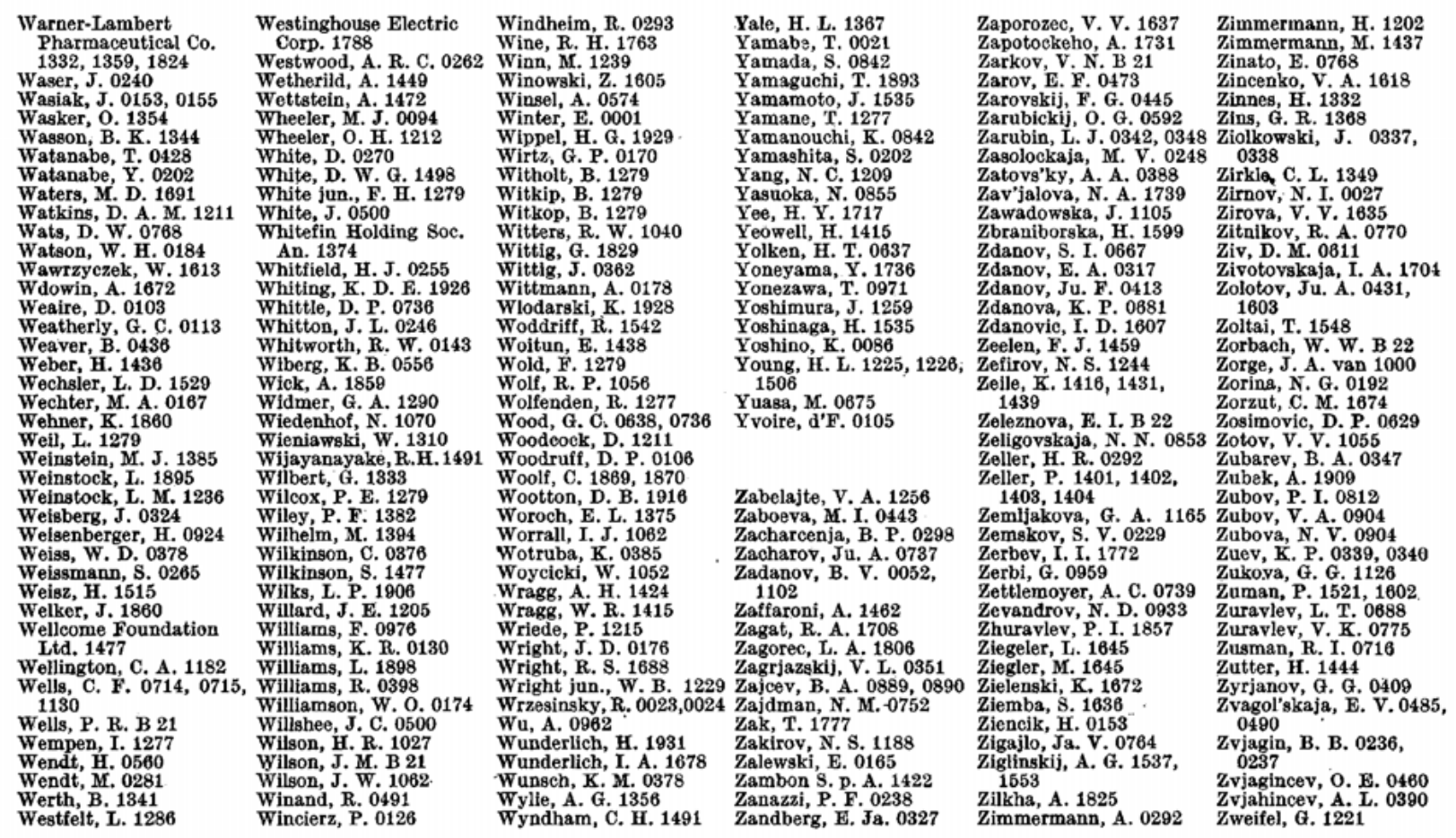

Patentregister

\begin{tabular}{|c|c|c|c|c|c|c|c|c|}
\hline Nr. & Ref.-Nr. & Bezugspatent & Nr. & Ref.-Nr. & Bezugspatent & Nr. & Ref.-Nr. & Bezugspatent \\
\hline \multicolumn{3}{|c|}{ Australische Patente - Austral.P. } & 1020805 & 1427 & (D.P.[DDR] 42 938) & \multicolumn{3}{|c|}{ Canadische Patente - Can.P. } \\
\hline $\begin{array}{l}249667 \\
252721\end{array}$ & & (F.P. 1305 119) & $\begin{array}{l}1025220 \\
1025699\end{array}$ & $\begin{array}{l}1919 \\
1412\end{array}$ & $\begin{array}{l}\text { (Oe.P. } 240362) \\
\text { (D.A. } 1210875\end{array}$ & 690924 & 1862 & (D.A.S. 1197864 ) \\
\hline 252721 & 1797 & (E.P. 1302436$)$ & i 029326 & 1417 & (D.P.[DDR] 45 356) & 694520 & 1906 & $\begin{array}{l}\text { (U.S.P. } 3121003 \text { ) } \\
\text { (Brit.P. } 962 \text { 925) }\end{array}$ \\
\hline $\begin{array}{r}745 \\
254529\end{array}$ & $\begin{array}{l}1869 \\
1892\end{array}$ & $\begin{array}{l}\text { (U.S.P. } 3049573) \\
\text { (F.P. } 1295734)\end{array}$ & $\begin{array}{l}1031370 \\
1041346\end{array}$ & $\begin{array}{l}1833 \\
1488\end{array}$ & (NiederLP 122 318) & 695 & & (Brit.P. 962 925) \\
\hline 255198 & 1895 & $\begin{array}{l}(F . P .1 \\
(F . P .1315274)\end{array}$ & $\begin{array}{l}1041846 \\
1048798\end{array}$ & $\begin{array}{l}1400 \\
1849\end{array}$ & (N1ederi.P. 122318 ) & \multirow{2}{*}{\multicolumn{3}{|c|}{$\begin{array}{l}\text { Auslegeschriften der Patentanmeldungen } \\
\text { des Deutschen Patentamtes München - D.A.s. }\end{array}$}} \\
\hline 260572 & 1913 & (D.A.S. 1212088 ) & 1054330 & 1780 & & & & \\
\hline $\begin{array}{r}263596 \\
639\end{array}$ & $\begin{array}{l}1402 \\
1399\end{array}$ & $\begin{array}{l}\text { (D.A.S. } 1215725) \\
\text { (Brit.P. } 974983)\end{array}$ & $\begin{array}{l}1057831 \\
1005866\end{array}$ & $\begin{array}{l}1861 \\
1850\end{array}$ & (D.P.[DDR] 43 203) & 1204654 & $\cdot 1868$ & (F.P.1300 459) \\
\hline 790 & 1881 & & $\begin{array}{l}1008000 \\
1060523\end{array}$ & 1422 & (D.A.S. 1201845$)$ & 1213836 & 1485 & (Schwz.P. 388288) \\
\hline 264634 & $\begin{array}{l}1403 \\
1418\end{array}$ & (Brit.P. 989259$)$ & 1062788 & $\begin{array}{l}1866 \\
1860\end{array}$ & (D.P. [DDR $]$ 43 244) & 1215155 & 1915 & (D.P.[DDR] 43 044) \\
\hline 269623 & $\begin{array}{l}1416 \\
1467\end{array}$ & $\begin{array}{l}\text { (Brit.P. 928 007) } \\
\text { (D.A.s. 1 121 611) }\end{array}$ & 1068887 & $\begin{array}{l}1859 \\
1386\end{array}$ & & 1221620 & $\begin{array}{l}1430 \\
1907-207\end{array}$ & $\begin{array}{l}\text { (D.P.[DDR] } 43 \text { 047) } \\
\text { (F.P.1 295 395) }\end{array}$ \\
\hline 270854 & 1449 & (Brit.P. 963 964) & 1070750 & 1901 & (D.A.S. 1211 182) & 1221623 & 1870 & (F.P. 1294973 ) \\
\hline 909 & 1431 & (Oe.P. 230889 ) & 1072705 & 1871 & (D.A.S. 1207 371) & 624 & 1869 & (U.S.P. 3049 573) \\
\hline 272161 & 1406 & (Brit.P. 968 254) & 1075267 & 1899 & (D.A.S. 1211 174) & 1223975 & 1880 & (D.P. [DDR] 42 228) \\
\hline 397 & 1440 & (Brit.P. 996 062) & 1077625 & 1889 & (D.P.[DDR] 43 199) & 1225662 & 1397 & (Brit.P. 1022031$)$ \\
\hline \multirow{3}{*}{\multicolumn{3}{|c|}{ Belgische Auslegeschriften - Belg.A.S. }} & $\begin{array}{r}982 \\
1082\end{array}$ & 1912 & (U.S.P. 3255 199) & 1228602 & 1879 & (F.P.1311 244) \\
\hline & & & $\begin{array}{l}1082164 \\
1008596\end{array}$ & $\begin{array}{l}1856 \\
1474\end{array}$ & (F.P. 1432 569) & 1229534 & $\begin{array}{l}1917 \\
1886\end{array}$ & $\begin{array}{l}\text { (D.P.[DDR] } 30874 \text { ) } \\
\text { (D.P.[DDR] } 43 \text { 244) }\end{array}$ \\
\hline & & & 597 & 1474 & (F.P. 1432 589) & 1239315 & 1401 & (Brit.P. 993 036) \\
\hline 625215 & 1457 & (U.S.P. 3118 814) & 1095052 & $\begin{array}{l}1420 \\
1435\end{array}$ & (D.P.[DDR] 49 848) & $\begin{array}{l}1241446 \\
1243187\end{array}$ & $\begin{array}{l}1904 \\
1903\end{array}$ & $\begin{array}{l}\text { (Brit.P. } 940 \text { 928) } \\
\text { (D.P.[DDR] 29 409) }\end{array}$ \\
\hline 672011 & 1934 & & 1097603 & 1847 & & 1247314 & 1897 & (D.P. (DDR 42176 ) \\
\hline & & & 1098349 & 1818 & & 1249871 & 1442 & (D.P.'DDR1 39 143) \\
\hline \multirow{2}{*}{\multicolumn{3}{|c|}{ Britlsche Patente - Brit.P. }} & 725 & 1851 & & 1250828 & 1434 & (Brit.P. 1011 554) \\
\hline & & & & 1855 & & 1252192 & 1861 & (D.P.[DDR] 43 203) \\
\hline & & (F.P. 1 311 692) & $\begin{array}{l}1099642 \\
1104591\end{array}$ & $\begin{array}{l}1852 \\
1788\end{array}$ & & $\begin{array}{r}1253489 \\
689\end{array}$ & $\begin{array}{l}1891 \\
1490\end{array}$ & $\begin{array}{l}\text { (Brit.P. 964 224) } \\
\text { (Brit.P. 994 B31) }\end{array}$ \\
\hline 948687 & 1877 & (F.P. 1315258$)$ & 1108231 & 1787 & & 1254631 & 1443 & (D.P.[DDR] 38 043) \\
\hline 8696 & 1882 & (Aust.P. 250 667) & 1112568 & 1791 & & 1259856 & 1795 & (F.P. 1305119$)$ \\
\hline 414 & 1485 & (Schwz.P. 388 288) & 1113219 & 1786 & & 1262259 & 1893 & (F.P. 1317707 ) \\
\hline 971183 & 1468 & (F.P. 1281012$)$ & 1117031 & -1828 & & 985 & 1793 & \\
\hline 686 & 1876 & (F.P. 1335423 ) & 635 & 1827 & & 1265321 & 1931 & \\
\hline 978855 & 1486 & (F.P. 1309831 ) & 1118085 & 1820 & & & 1395 & $\begin{array}{l}\text { (Brit.P. } 905 \text { 903) } \\
\text { (Brit.P. 834 984) }\end{array}$ \\
\hline 8634 & 1898 & (F.P. 1299752$)$ & 499 & 1857 & & 1268620 & 1454 & $\begin{array}{l}\text { (Brit.P. 834 984) } \\
(\mathrm{D} . \mathrm{P}[\mathrm{DDR}] \text { 41 659) }\end{array}$ \\
\hline 989883 & 1873 & (U.S.P. 3062892 ) & 1119069 & 1836 & & 1269620 & 1910 & $\begin{array}{l}\text { (D.P.[DDR] 41 659) } \\
\text { (U. P. 3 014 938) }\end{array}$ \\
\hline 994414 & 1892 & (F.P. 1295734$)$ & $\begin{array}{r}070 \\
1902\end{array}$ & 1837 & & 1270041 & 1471 & (U.S.P. 3014 938) \\
\hline $\begin{array}{r}996079 \\
1000781\end{array}$ & $\begin{array}{l}1461 \\
1441\end{array}$ & (D.A.S. 1195 748) & 1120823 & 1821 & & 1271083 & $\begin{array}{l}1782 \\
1781\end{array}$ & \\
\hline 1002234 & 1445 & (D.P.[DDR] 36 873) & $\begin{array}{r}1121413 \\
182\end{array}$ & $\begin{array}{l}1845 \\
1832\end{array}$ & & 1273529 & $\begin{array}{l}1927 \\
1927\end{array}$ & (Brit.P. 1084 610) \\
\hline 1010582 & 1487 & (Oe.P. 242 139) & 1123457 & 1824 & & 1274090 & 1784 & \\
\hline 1012701 & 1865 & (F.P.1313 732) & 671 & 1853 & & 129 & 1439 & (Brit.P. 1054 539) \\
\hline 955 & 1373 & & 878 & 1858 & & 582 & 1433 & $\begin{array}{l}\text { (Ung.P. } 150890) \\
\text { (D.P. }[D D R] 32888)\end{array}$ \\
\hline 956 & 1373 & & 942 & 1835 & & & & (D. .[DDR] 32 888) \\
\hline
\end{tabular}

